\title{
Erratum to: Heparanase expression in term placentas of diabetic patients and healthy controls
}

\author{
Doerte W. Luedders • Diana Bundschuh • \\ Amadeus Hornemann · Jana-Christin Hoerster • \\ Philipp Boemicke • Frank Köster • Michael K. Bohlmann
}

Published online: 28 October 2010

(C) Springer-Verlag 2010

\section{Erratum to: Arch Gynecol Obstet \\ DOI 10.1007/s00404-010-1636-5}

The authors regret that a typographic mistake occurred in the "Materials and methods" section of online published article. Instead of

"According to our prior analysis (N-Query advisor, Statcon, Witzenhausen, Germany), 33 patients in each arm of the study were needed in order to achieve a power of $80 \%$ with an $\alpha=0.05$."

The correct sentence is

"According to our prior analysis (N-Query advisor, Statcon, Witzenhausen, Germany), 30 patients in each arm of the study were needed in order to achieve a power of $80 \%$ with an $\alpha=0.05$."

The online version of the original article can be found under doi:10.1007/s00404-010-1636-5.

D. W. Luedders - D. Bundschuh - J.-C. Hoerster

P. Boemicke · F. Köster · M. K. Bohlmann ( $\square)$

Department of Obstetrics and Gynecology,

University Hospital of Schleswig-Holstein, Campus Luebeck,

Ratzeburger Allee 160, 23538 Lübeck, Germany

e-mail: michael.bohlmann@uk-sh.de

\section{A. Hornemann}

Department of Obstetrics and Gynecology,

University Hospital Mannheim, University of Heidelberg,

68167 Mannheim, Germany 